\title{
SOME SIMULATIONS ON THE PORTFOLIO RISK AND RETURN: A METHODOLOGICAL NOTE
}

\section{FITIM DEARI}

\author{
Associated Professor, \\ South East European University, Republic of North Macedonia \\ f.deari@seeu.edu.mk.
}

\section{IZET ZEQIRI}

\author{
Full Professor, \\ South East European University, Associate Member of the \\ Macedonian Academy of Sciences and Arts, Republic of North Macedonia \\ i.zeqiri@seeu.edu.mk.
}

\section{SADRI ALIJI}

\section{Associated Professor,}

South East European University, Republic of North Macedonia

s.aliji@seeu.edu.mk

For citation: Deari F., Zeqiri I., Aliji S. (2019), Some Simulations On The Portfolio Risk And Return: A Methodological Note, Globalization And Business, №7, pp. 59-62. https://doi.org/10.35945/gb.2019.07.007

\section{INTRODUCTION AND DEFINITION OF THE PROBLEM}

Investing either on short or long-term securities is not an easy decision. Decision makers are in the front of many alternatives in which money can be invested. In the principle, decision making process has to study the relationship between risks and returns. Higher risks should be compensated by higher returns and thus different investors will prefer different investments. While some will prefer a combination of higher risk-return, other will prefer a combination of lower risk-return. But, both face with the same problem: how to distribute investing funds among selected alternatives? With other words, what are investing proportions per each alternative, i.e. security?

Let's consider an investor that has 10,000 Euros available to invest among two alternatives: (1) Agilent Technologies, Inc. (hereafter A) and (2) Barnes Group Inc. (hereafter B). Investor required $10 \%$ return from the overall investment, which is 1,000 Euros. Composition of an optimal portfolio means that $10 \%$ return will be realized on one hand and on other hand risk will be minimized. The problem with which an investor faces in this case is how to share 10,000 Euros: how much to invest on $A$ and $B$. Thus, the study tries to present effects that weight has on overall risk and return (portfolio risk and return). Moreover, the correlation coefficient between $A$ and $B$ should also be considered and lower coefficient provides better effect from diversification.

The rest of this paper is organized as following: 2. Data and methodology; 3 . Analysis, results and discussion; 4. Conclusions; and 5. References.

\section{DATA AND METHODOLOGY}

Time-series data covers the period from March 2010 to February 2018 downloaded from Yahoo Finance (https:// finance.yahoo.com/). For an experimental purpose Agilent Technologies, Inc. (A) and Barnes Group Inc. (B) are random- 
ly selected. From downloaded data we kept just adjusted prices, whereas other data as: open, high, low, close and volume we are not examined in this study. Data are selected on monthly terms and thus stock's returns are calculated. Data and analysis are performed using Excel. Totally 95 observations are examined.

Stock' return is calculated as: $\quad\left(P_{t}-P_{t-1}\right) / P_{t-1}$

and adjusted prices are used.

Another calculation would be: $\operatorname{Ln}\left[\left(P_{t}+D_{t}\right) / P_{t-1}\right]$

and for more see: Benninga (1997).

Covariance and correlation between stock A and B, and the portfolio variance are calculated as following and for more see: Bundo (2009):

$$
\begin{aligned}
& \operatorname{cov}_{i j}=\frac{1}{T} \sum_{i=1}^{T}\left(R_{i, t}-\bar{R}_{i}\right)\left(R_{j, t}-\overline{R_{j}}\right) \\
& \rho_{i j}=\frac{\operatorname{cov}_{i j}}{\sigma_{i} \sigma_{j}} \\
& \sigma_{p}^{2}=\sum_{i=1}^{N} \sum_{j=1}^{N} w_{i} w_{j} \rho_{i j} \sigma_{i} \sigma_{j}
\end{aligned}
$$

\section{ANALYSIS, RESULTS AND DISCUSSION}

In this section performed analysis and related discussion are presented. Table 1 presents selected summary statistics for both stocks. As it can be noticed stock $B$ offers higher return than stock $A$, but both have almost the same sample variance (0.6\%). On average, per each 100 Euros invested on stock $A$, there is 1.5 Euros return, respectively 1.7 Euros on stock B. Stock $A$ reached higher maximum than stock $B$, whereas almost both have similar minimum points. This makes stock $A$ to have range of 0.412 in comparison with $B$ of 0.381. In other words, based on this measure stock $A$ seems to be more risky than $B$. But, on the other hand stock $B$ has higher variance than stock $A$, i.e. $0.59 \%$ versus $0.55 \%$ (see on Table 1, results are presented as rounded numbers rather than percentages).

\begin{tabular}{|c|c|c|}
\hline Description & Return-Stock A & Return-Stock B \\
\hline Mean & 0.015 & 0.017 \\
\hline Standard Deviation & 0.074 & 0.077 \\
\hline Sample Variance & 0.006 & 0.006 \\
\hline Kurtosis & 0.850 & 0.239 \\
\hline Skewness & 0.298 & 0.158 \\
\hline Range & 0.412 & 0.381 \\
\hline Minimum & -0.175 & -0.172 \\
\hline Maximum & 0.237 & 0.209 \\
\hline Count & 95 & 95 \\
\hline
\end{tabular}

Table 1: Summary statistics

View as trend line, less or more stock A and stock B are moving on the same direction as it's presented on Figure 1.

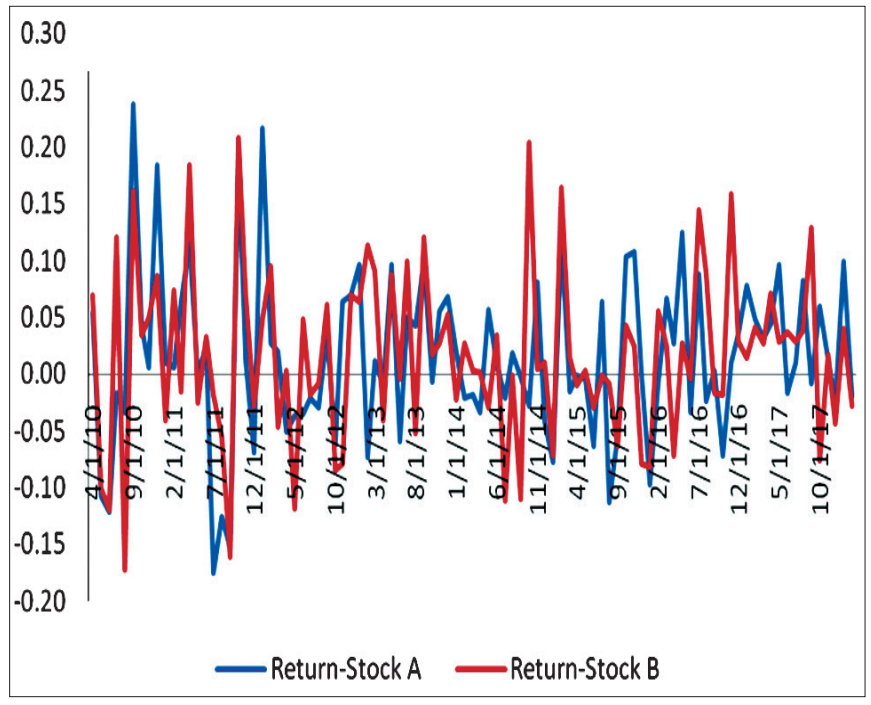

Fig. 1. Historical returns

Table 2 presents correlation between stock $A$ and stock $\mathrm{B}$, whereas Table 3 presents covariance. There is a positive correlation between selected stocks.

\begin{tabular}{|c|c|c|}
\hline & Return-Stock A & Return-Stock B \\
\hline Return-Stock A & 1.000 & \\
\hline Return-Stock B & 0.532 & 1.000 \\
\hline
\end{tabular}

Table 2: Correlation

As usual, investors would chose stocks or securities in general from companies in different business industries due to lower correlation coefficients. Lower return from one business industry is supposed to be compensated with higher return from another one. Thus, the target return or overall return is important, i.e. portfolio return to be achieved under the accepted risk rate.

\begin{tabular}{|c|c|c|}
\hline & Return-Stock A & Return-Stock B \\
\hline Return-Stock A & 0.005 & \\
\hline Return-Stock B & 0.003 & 0.006 \\
\hline
\end{tabular}

\section{Table 3: Covariance}

Moreover, totally five simulations are performed as presented on Table 4. From first to fourth simulation there are presented cases in which arbitrary are given weights, $30 \%$ of funds are invested on stock $A$ and $70 \%$ on stock $B$. In the first simulation, using the actual correlation coefficient of 0.5 , calculated portfolio variance is $0.5 \%$, respectively standard deviation $6.8 \%$. In the second simulation, correlation coefficient is 0.0 (neutral correlation) and thus portfolio standard deviation is $5.8 \%$. In the third simulation, correlation coefficient is 1.0 (perfect positive correlation) and thus portfolio standard deviation is $7.6 \%$. In the fourth simulation, there is a perfect negative correlation, i.e. -1.0 and calculated portfolio standard deviation is $3.1 \%$. 


\begin{tabular}{|c|c|c|}
\hline \multicolumn{3}{|c|}{ Initial data and simulation 1} \\
\hline Description & A & B \\
\hline Weight & 0.300 & 0.700 \\
\hline Correlation coefficient & 0.532 & \\
\hline Portfolio variance & 0.005 & \\
\hline Portfolio standard deviation & 0.068 & \\
\hline \multicolumn{3}{|c|}{ Simulation 2} \\
\hline Weight & 0.300 & 0.700 \\
\hline Correlation coefficient & 0.000 & \\
\hline Portfolio variance & 0.003 & \\
\hline Portfolio standard deviation & 0.058 & \\
\hline \multicolumn{3}{|c|}{ Simulation 3} \\
\hline Weight & 0.300 & 0.700 \\
\hline Correlation coefficient & 1.000 & \\
\hline Portfolio variance & 0.006 & \\
\hline Portfolio standard deviation & 0.076 & \\
\hline \multicolumn{3}{|c|}{ Simulation 4} \\
\hline Weight & 0.300 & 0.700 \\
\hline Correlation coefficient & -1.000 & \\
\hline Portfolio variance & 0.001 & \\
\hline Portfolio standard deviation & 0.031 & \\
\hline \multicolumn{3}{|c|}{ Simulation 5} \\
\hline Optimal weight & 0.536 & 0.464 \\
\hline Correlation coefficient & 0.532 & \\
\hline Portfolio variance & 0.004 & \\
\hline Portfolio standard deviation & 0.066 & \\
\hline
\end{tabular}

Table 4: Simulation of correlation and weight

Results denote clearly that as the correlation coefficient is lower, the portfolio risk is measured by variance and the standard deviation becomes lower too. Theoretically, there is no benefit from the diversification when correlation is +1 as it evidenced here and better result is obtained when correlation is -1 . In the condition of perfect negative correlation, portfolio standard deviation is $3.1 \%$, which is smallest from all other simulations.

Finally, the fifth simulation presents the case that with actual data the best solution is to invest $53.6 \%$ on stock $A$ and $46.4 \%$ on stock $B$ for an investor which attempts to minimize risks. These percentages are optimal weights or proportions how to share funds among both selected stocks. With optimal weights, overall return will be $1.56 \%$, whereas on other cases will be $1.60 \%$. Thus, in this case an investor gets something lower return from portfolio since the risk is slightly decreased comparing with the first simulation. Optimal weights are found using Excel Solver. Otherwise, optimal weight on stock $A$ (then investing on stock $B$ is: $1-w A$ ) can be found using Lagrange function (multiplier) (see for example: Bundo, 2009; Deari, 2015) or other calculation ways (see for example: Bodie, Kane, Marcus, 2002; Roychoudhury, 2007).

Figure 2 presents all simulations performed based on correlation coefficients.

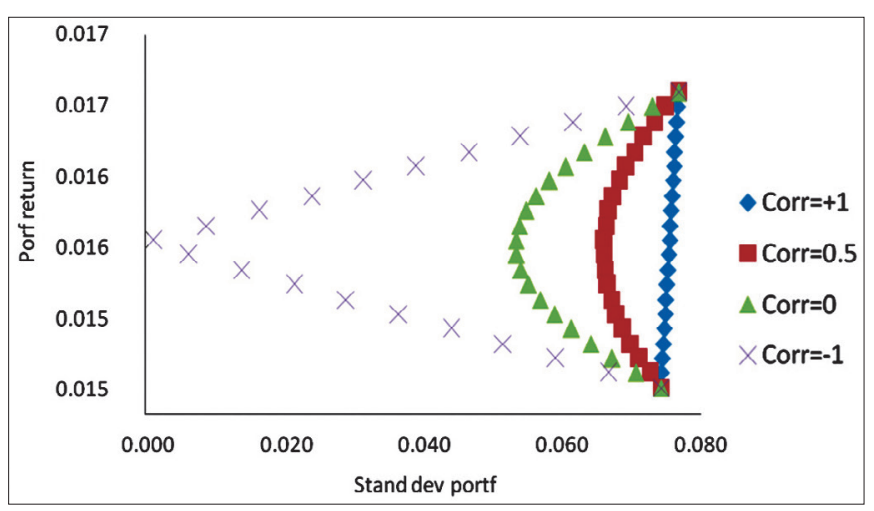

Fig. 2. Portfolio risk and return

\section{CONCLUSION}

This study applied an experimental analysis showed that the risk and the return from a portfolio is influenced by the correlation coefficient and respectively investing weights. Selecting securities with lower correlation coefficients should be an element in the decision making process, as well how to share funds in an optimal way.

\section{REFERENCES:}

1. Benninga, S. (1997). Financial Modeling, Uses Excel. Cambridge: Massachusetts Institute of Technology Press.

2. Bodie, Z., Kane, A., Marcus, J. A. (2002). Investments. Boston: McGraw-Hill Irwin.

3. Bundo, Sh. (2009). Drejtim Portofoli. Tiranë: albPAPER.

4. Deari. F. (2015) “Portfolio Composition: A Methodological Solution Using Lagrange Multiplier", ICESOS'15, Sarajevo.

5. Roychoudhury, S. (2007). "The optimal portfolio and the efficient frontier", National Science Foundation. [Online] 


\section{SOME SIMULATIONS ON THE PORTFOLIO RISK AND RETURN: A METHODOLOGICAL NOTE}

\section{FITIM DEARI}

\section{Associated Professor,}

South East European University, Republic of North Macedonia

f.deari@seeu.edu.mk.

\section{IZET ZEQIRI}

\section{Full Professor,}

South East European University, Associate Member of

the Macedonian Academy of Sciences and Arts, Republic of North Macedonia

i.zeqiri@seeu.edu.mk.

\section{SADRI ALIJI}

\section{Associated Professor,}

South East European University, Republic of North Macedonia

s.aliji@seeu.edu.mk

\section{KEYWORDS: INVESTMENT, CORRELATION, WEIGHT, PORTFOLIO, STOCK.}

For citation: Deari F., Zeqiri I., Aliji S. (2019), Some Simulations On The Portfolio Risk And Return: A Methodological Note, Globalization And Business, №7, pp. 59-62. https://doi.org/10.35945/gb.2019.07.007

\section{SUMMARY}

In this study we try to demonstrate mainly from the methodological and pedagogical perspective how investment weights and the correlation between securities are manifested on the portfolio risk and return. Empirical data are examined from 2010 to 2018 and for experimental purpose two companies are randomly selected. Totally five simulations are performed using Excel.

The fifth simulation presents the case of optimal proportions for an investor which efforts to minimize the portfolio risk. 